he had passed three hours before. The Waboni tribe, who live by hunting, and use the bow and arrow, occupied the thick woods of the lower river. Above them the curves became more gentle, and the Gusha district was reached, where the people cultivated the land, which was cleared by burning; and for a hundred miles the Kenia's furnaces were fired with the dead trees which had been killed, but left unburnt by the fire. Cotton is cultivated as well as food plants, and there is a primitive system of weaving. Above Bilo, and about ros miles from the sea, a branch was found to run off from the main river to the south-west through very dense forests. This is probably the Sheri, which reaches the sea midway between Lamu and Kismayu; the land between this and the Juba mouth being probably of deltaic origin. This branch was explored in a boat for twenty miles. The dense forests formed a broad belt on both sides on the river, and after steaming for five days through un. inhabited woods the Kenia suddenly emerged into open country on August 2. The people were of very mixed race, friendly and well supplied with all sorts of food. Hills began to appear, and the river grew shallower, until on August Io the steamer moored to the bank opposite Bardera. Here the Sultan forbad a landing, and the people, who numbered about 1200 , were hostile, but ultimately peace was arranged, and one of the subordinate sheiks accompanied the Kenia to the rapid, where the river sweeps between steep rocky hills 300 to 400 feet high. There are three channels in the rapids, but at the time of the visit none was navigable, and the natives reported a waterfall over a ledge of rock about four hours' march further up, in latitude $2^{\circ} 34^{\prime} \mathrm{N}$. The wreck of the Guelph was visited and examined, but the rapid falling of the water made it necessary to hasten back to the sea. The climate throughout was found agreeable, and there were few mosquitoes. The river does not overflow, so there are no malarial swamps along the banks.

\section{BREATH FIGURES.'}

FIFTY years back Prof. Karsten, of Berlin, placed a coin upon glass, and by electrifying it made a latent inpression, which revealed itself when breathed upon. About the same time Mr. W. R. (now Sir W. R.) Grove made simtlar impressions with simple paper devices, and fixed them so as to be always visible. A discussion of Karsten's results occurs in several places, but I have not been able to find details of his method of performing the experiment. During my attempts to repeat it some effects have appeared which seem to be new and worthy of record.

After many trials I found the following method the most successful :-A glass plate, six inches square, is put on the table for insulation : in the middle lies a coin with a strip of tinfoil going from it to the edge of the glass : on this coin lies the glass to be impressed, four or five inches square, and above it a second coin. It is essential to polish the glass scrupulously clean and dry with a leather : the coins may be used just as they usually are, or chemically cleansed, it makes no difference. The tinfoil and the upper coin are connected to the poles of a Wimshurst machine which gives three or four inch sparks. The handle is turned for $t w$, minutes, during which one-inch sparks must be kept passing at the poles of the wachine. On taking up the glass one can detect no change with the eye or the microscope ; but when either side is breathed upon, a clear frosted picture appears of that side of the coin which had faced it: even a sculptor's mark beneath the head may be read. For convenience those parts where the breath seems to adhere will be called white, the other parts black. In this experiment the more projecting parts of the coin have a black counterpart, "but there is a fine gradation of shade to correspond with the depth of cutting in the device : the soft undulations of the head and neck are delicately reproduced.

The microscope shows that moisture is really deposited over the whole surface, the size of the minute water granulation increasing as the point of the picture is darker in shade.

There seẹms to be no change produced by the use of coins of different metals.

If sparking is allowed across the glass instead of at the poles of the machine, traces of metal are sometimes deposited beyond the disk of the coin, but not within it.

I Paper read by Mr. W. B. Croft before the Physical Society of London on June $24,1892$.

No. [208, vOL 47$]$
Around the disk is a black ring quarter inch broad: some times the milling of the coin causes radial lines across this halo.

If carefully protected there appears to be no limit to the permanence of the figures, but commonly they are gradually obscured by the dust gathered up after being often breathed upon: some of the early ones, done more than two years back, are still clear and well defined in the detail.

It is possible to efface them with some difficulty by rubbing with a leather whilst the glass is moist. They are best preserved by laying several together when dry and wrapping them in paper: they are not blurred by this contact.

It is a curious fact that certain developments take place after a lapse of some weeks or months. The dark ring around the disk gradually changes into a series of three or four, black and white alternately; other instances of such a change will be noted below.

Let it be noticed that in coin pictures the object is near to, but not in contact with, the glass : for in the best specimens the rim of the coin keeps the inner part clear of the surface.

Obviously a small condenser is made by the coins: it is not essential; at the same time images made by a single coin, put to a single pole, are inferior.

The plan which gives the surest and most beautiful results is to place five or six coins, lying in contact side by side in a cross or star, on either side of the glass: it is not necessary that each coin should exactly face one on the other side.

There has not appeared any distinction between the figures made by positive and negative electricity.

When several coins are placed side by side, touching one another, there appear in the spaces between them, which are mostly black, well-defined white lines, common tangents to the circular edges of the coins. If these are of equal size the lines are straight otherwise they are curved, concave towards a smaller coin. They seem to be traces in that plane of the loci of intersection of equipotential surfaces.

Similar effects are obtained when coins a nd glasses are piled up alternately, and the outer coins are put to the poles of the machine. With six glasses and seven coins perfect images have been formed on both sides of each glass. With eight glasies the figures were imperfect; but there is little doubt this could be improved by continued trials as to the amount of electricity applied.

If several glasses are superposed and coins are applied to the outer surfaces, there are only the two images at the outside. After the electrification there is a strong cohesion between the plates.

It requires some practice to manage the electrification so as to produce the best results. There are two forms of failure which present interesting features. Sometimes a picture comes out with the outlines dotted instead of being continuous. At other times, if the electrification is carried too far, the impression comes out wholly black; but on rubbing the glass when dry with a leather the excess is somehow removed. Naturally it is difficult to rub down exactly to the right point, but $I$ have succeeded on several occasions in developing from a blank all the fine detail of elaborate coins.

Here, again, we have another instance of the development by lapse of time, for an over-excited piece of glass usually gives a clear picture after an interval of a day or two.

Impressions from stereotype plates have been taken of which the greater part is legible : the distinctness usually improves after a few days. In default of a second plate, a piece of tin-foil about the same size should be put on the opposite side of the glass.

Sheet and plate glass of various thicknesses have been used without any noticeable change either in the treatment or the results.

I have put an impressed glass on a photographic plate in the dark, but did not get any result on developing : my imperfect skill in photographic matters leaves this experiment inconclusive.

Probably all polished surfaces may be similarly affected: a plate of quartz gives the most perfect images, which retain their freshness longer than those on glass.

Mica and gelatine give poorer resulıs : it is not possible to polish the surface to the necessary point without scratching it.

On metal surfaces fairly good impressions can be produced if, as Karsten advises, oiled paper is put between the coin and the surface.

In the order of original discovery the figures noticed by Peter Riess should come first. He discusses a breath-track made on 
glass by a feeble electrical discharge; as well as two permanent marks, noticed by Ettrick, which betray a disintegration of the surface.

I have found that when a stronger discharge is employed more complex phenomena of a similar kind are produced. A six-inch Wimshurst machine is arranged with extra condensers, as if to pierce a piece of glass. If this is about four inches square the spark will generally go round it. For a day, more or less, there is only a bleared watery track, $\frac{3}{10}$ inch wide, when the glass is breathed upon ; but after this time others develop themselves within the first, a fine central black line with two white and two black on either side, the total breadth being the original $\frac{3}{10}$ inch. These breath-lines do not precisely coincide in position with the permanent scars, but the central one is almost the same as a permanent mark, which the micros cope shows to be the surface of glass fractured into small squares of considerable regularity: on either side is a grey-blue line always visible, which Riess ascribes to the separation of the potash. After several months I found two blue lines on either side, which I believe were not visible at first. Of course these blue lines may be seen on most Leyden jars, where they have discharged themselves across the glass.

In I842 Möser, of Königsberg, produced figures on polished surfaces by placing bodies with unequal surfaces near to them; the action was ascribed to the power of light, and his results were compared with those of Daguerre. Möser says, "We cannot therefore doubt that light acts uniformly on all bodies, and that, moreover, all bodies will depict themselves on others, and it only depends on extraneous circumstances whether or not the images become visible." In general, the multitude of images would make confusion; it can only be freshly polished surfaces that are free to reveal single definite impressions. However great Möser's assumption may be, there are many achievements of modern photography that would be as surprising if they were not so familiar. I have not the means of knowing the precise form of Möser's methods : in the experiments which follow there is usually contact and light pressure, and if they are not wholly analogous, they may for that cause help to generalize the idea: in none of these is electricity applied.

A piece of mica is freshly split, and a coin lightly pressed for thirty seconds on the new surface : a breath-image of the coin is left behind. At the same time it may be noticed that the breath causes abundant iridescence over the surface, whilst it is in a fresh state. It is not clear how the electricity of cleavage can have an active agency in the result.

It is familiar to most people that a coin resting for a while on glass will give an outline of the disk, and sometimes faint traces of the inner detail when breathed upon.

An examination-paper, printed on one side, is put between two plates of glass and left for ten hours, either in the dark or the daylight : a small weight will keep the paper in continuous contact, but this is not necessary if thick glass is used. A perfect breath-impression of the print is made, not only on the glass which lay against the print, but also on that which faced the blank side of the paper. Of course the latter reads directly, and the former inversely; the print was about one year old, and presumably dry.

More often both impressions are white, sometimes one or other or both are black. At other times the same one may be part white and part black, and they even change while being examined.

During a sharp frost with east winds early in March, 1890 , these impressions of all kinds were easy to produce, so as to be quite perfect to the last comma ; but in general they are difficult, more especially those from the blank side.

At the best period those from the hlank side of the paper were white and very strong; also there were white spots and blotches revealed by the breath. They seemed to correspond with slight variations in the structure of the paper, and suggest an idea that the thickness of the ink or paper makes a minute mechanical indentation on the molecules: the state of these is probablytender and sensitive under certain atmospheric conditions, as happens with steel in times of frost.

The following experiments easily succeed at any time:- Stars and crosses of paper are placed for a few hours beneath a plate of glass: clear white breath-figures of the device will appear. A piece of paper is folded several times each way to form small squares, then spread out and placed under glass : the raised lines of the folds produce white breath-traces, and a letter weight that was above leaves a latent mark of its circular rim.

No. 1208 , VOL. 47$]$
Some writing is made on paper with ordinary ink and well dried : it will leave a very lasting white breath-image after a few hours' contact. If, with an ivory point, the writing is traced with slight pressure on glass, a black breath-image is made at once. Of course this reads directly, and the white one inversely. It is convenient to look through the glass from the other side for inverse impressions, so as to make them read direct.

Plates of glass lie for a few hours on a table-cover worked with sunflowers in silk: they acquire strong white figures from the silk.

In most cases I have warmed the glass, primarily for the sake of cleansing it from moisture ; but $\mathrm{I}$ have often gone to a heat beyond what this needs, and think that the sensitiveness has been increased thereby.

It is not easy to imagine what leads to the distinction between black and white, different substances act variously in this respect. I have placed various threads for a few hours under a piece of glass, which lay on them with light pressure : wool gives black, silk white, cotton black, copper white. A twist of tinsel and wool gives a line dotted white and black; after a time these traces show signs of developing into multiple lines as in the spark figures.

Two cases have been reported to me where blinds with embossed letters have left a latent image on the window near which they lay ; it was revealed in misty weather, and had not been removed by washing. I have not had a chance to see these for myself, but both my informants were accustomed to scientific observation.

A glass which has lain above a picture for some years, but is kept from contact by the mount, will often show on its inner side an outline of the picture, always visible without breath. It seems to be a dust figure easily removed : possibly heat and light have loosened fine paint particles, and these have been drawn up to the glass by the electricity made in rubbing the outer side to clean it. The picture must have been well framed and sealed from external influences ; most commonly dust and damp get in and obscure such a delicate effect.

I am not able to suggest simple causes for these varied effects. I am not inclined to think, except in the case of water-colours, which is hardly part of the enquiry, that there is a definite material deposit or chemical change; one cannot suppose that imperceptible traces of grease, ineradicable as they may be, would produce complete and delicate outlines. The cleaning off of impressions may at first seem to indicate a deposit; but this renewal of the surface might rather be like smoothing out an indented tin-foil surface: such a view might explain the case where a blank over-electrified disk is developed into fine detail. The electrified figures seem to point to a bombardment, which produces a molecular change, the intensity of electricity bringing about quickly what may also be done by slow persistent action of mechanical pressure. At present it seems as if most of the phenomena cannot be drawn out from the unknown region of molecular agency.

While experimenting I was not within reach of references to former researches, but I have since done my best to find them out, and to indicate all I have learnt in the body of my paper.

Poggendorff, vol. Ivii. p. 492 ; translated in Archives de l'Electricité, 1842, p. 647.

Riess' "Electrische Hauchfiguren" in "Repertorium der Physik"; translated in Archives de l'Electricité, 1842, p. $59 \mathrm{I}$.

Reiss" "Die Lehre von der Reibungs Electricität," vol. ii. pp. $221-224$.

Mascart, "Electricité Statique," vol, ii. p. 777.

Taylor's "Scientific Memoirs," vol, iii.

\section{SCIENTIFIC SERIALS}

American Journal of Science, December.-An experimental comparison of formule for total radiation between $15^{\circ} \mathrm{C}$. and $110^{\circ} \mathrm{C}$., by W. de Conte Steven:. The formula given by Dulong and Petit, by Rosetti, Stefan, and Weber, were tested for a compratively small range of differences by a determination of the heat radiated from an iron disc at a distance of about $30 \mathrm{~cm}$. from a thermopile. The results tended to show that H. F. Weber's formula (Sitzunssber., Berlin, 1888) agrees most closely with experiment. Stefan's formula, according to which the heat emitted in unit of time is proportional to the fourth power of the absolute temperature, is also fairly accurate, 